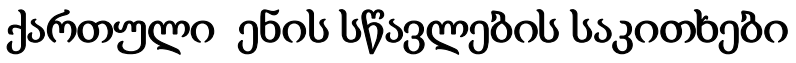

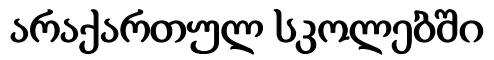

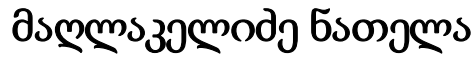

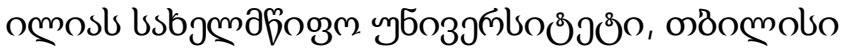

https://doi.org/10.52340/idw.2021.541

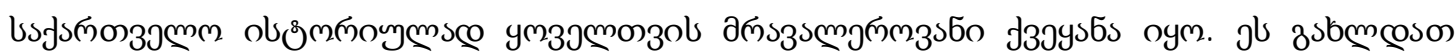

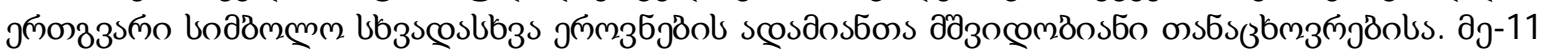

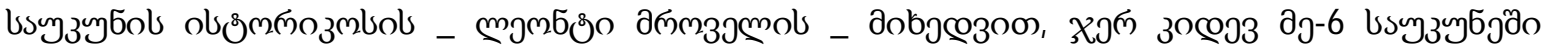

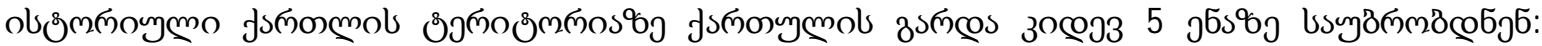

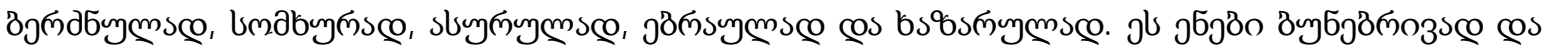

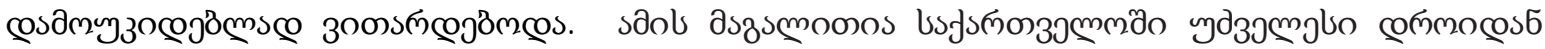

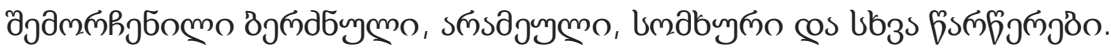

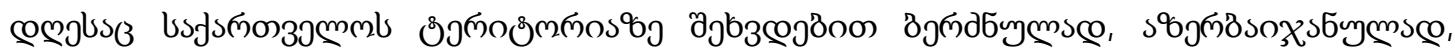

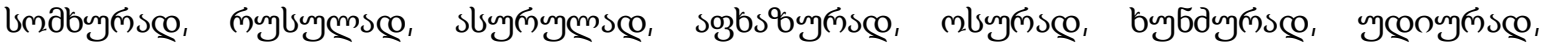

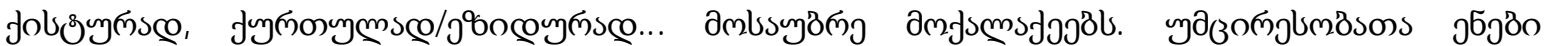

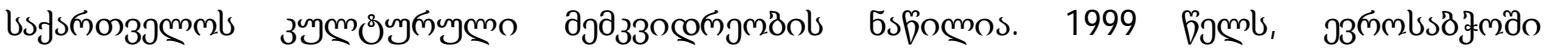

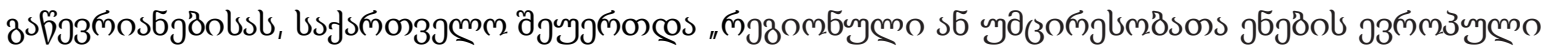

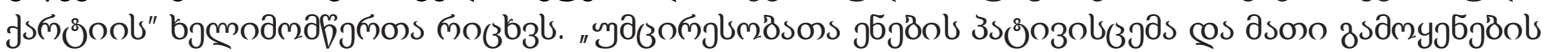

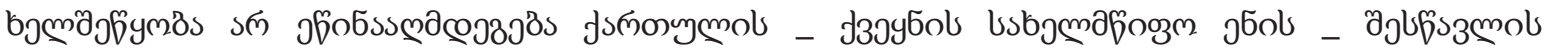

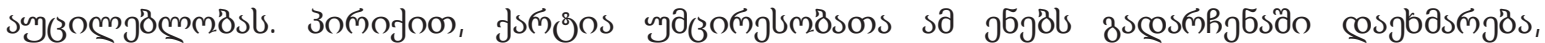

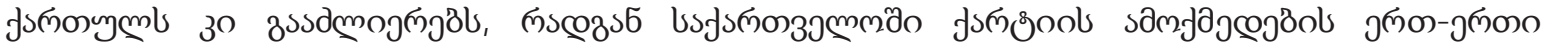

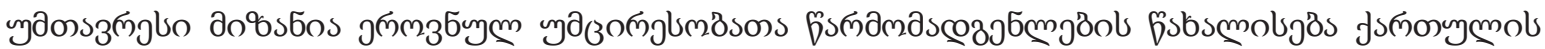

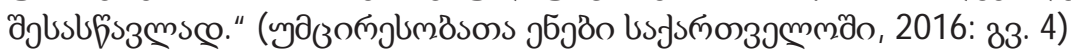

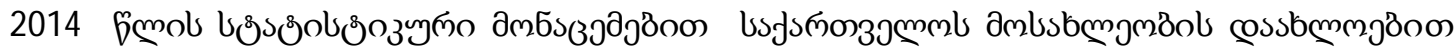

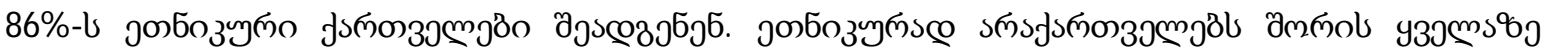

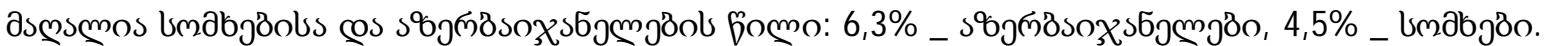

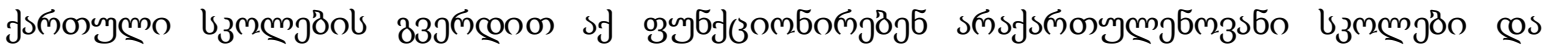

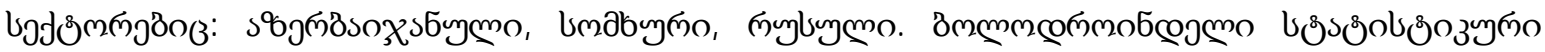

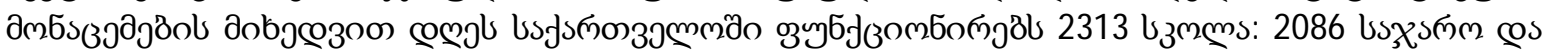

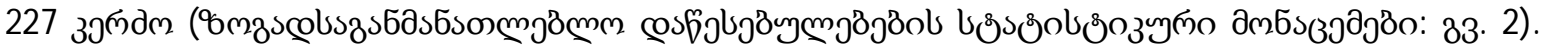

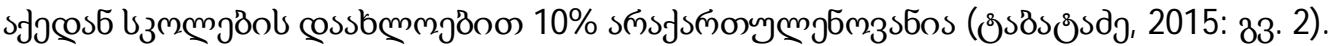

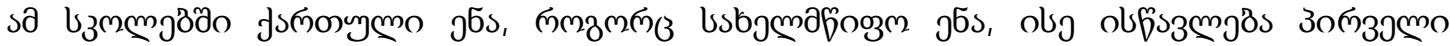

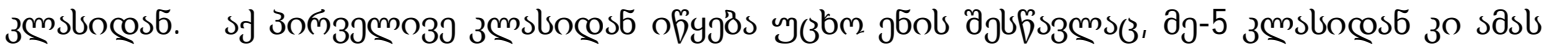

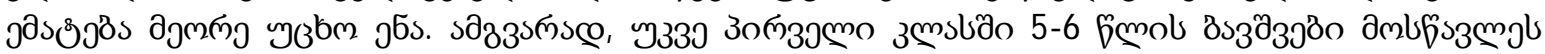

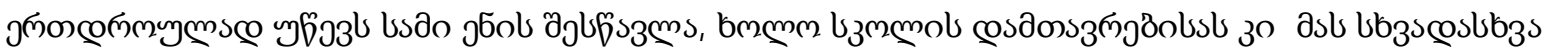

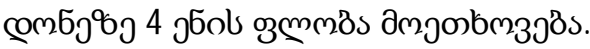

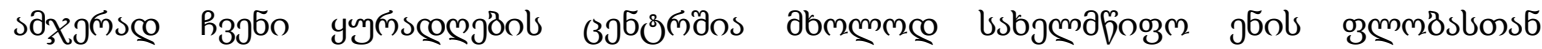

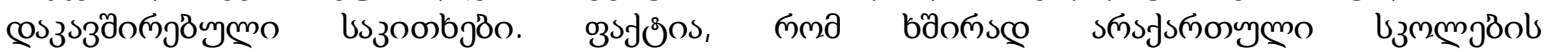

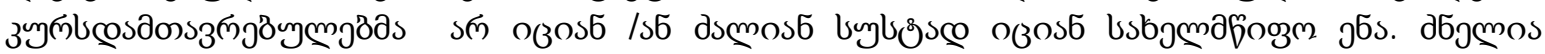

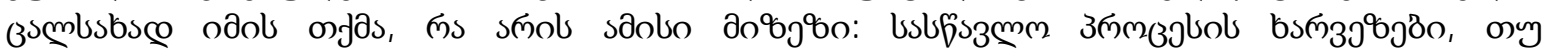

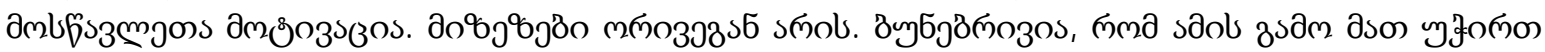




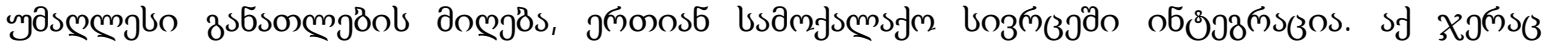

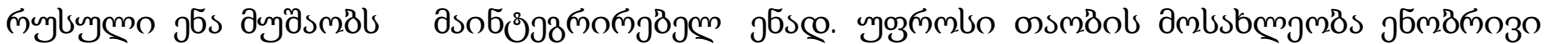

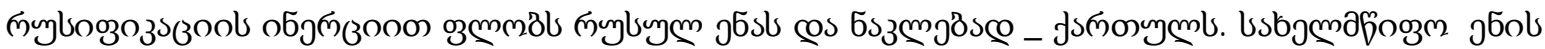

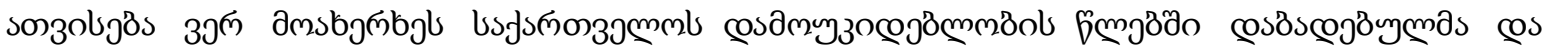

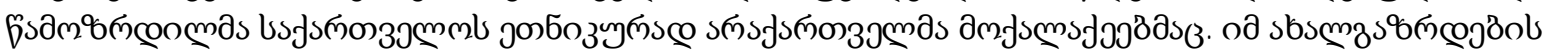

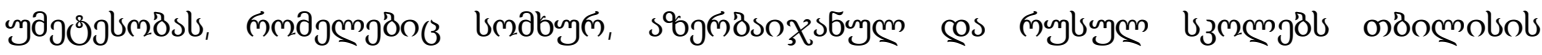

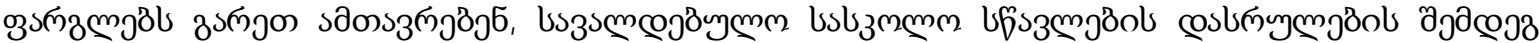

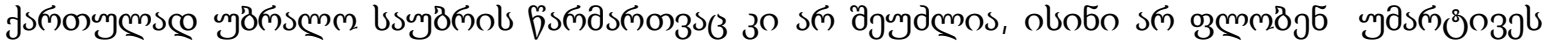

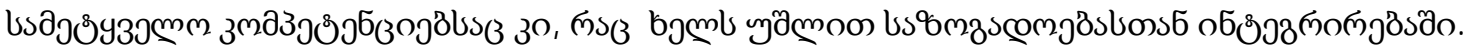

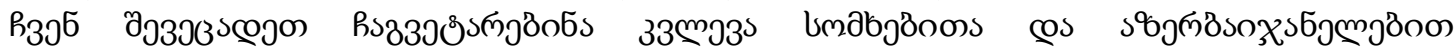

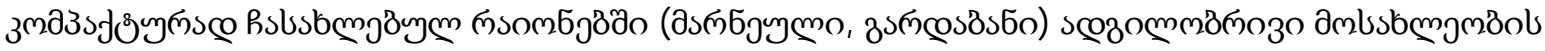

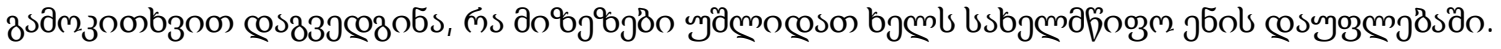

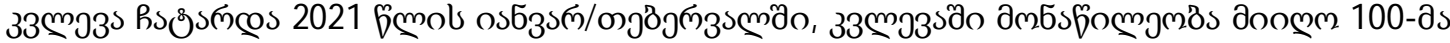
๓

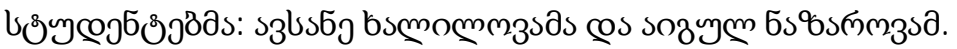

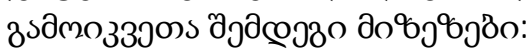

1. азиf́sз

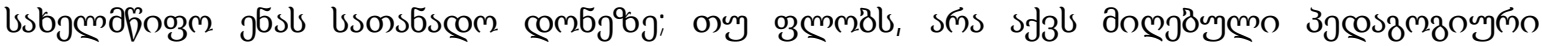

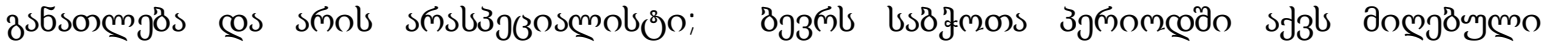

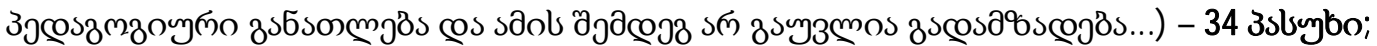

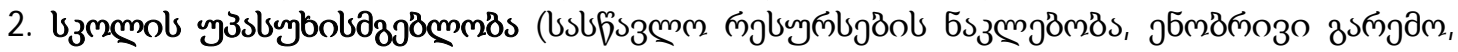

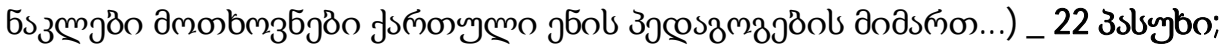

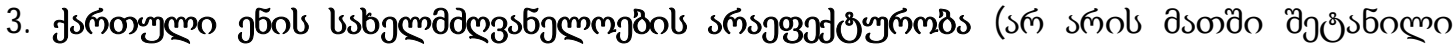

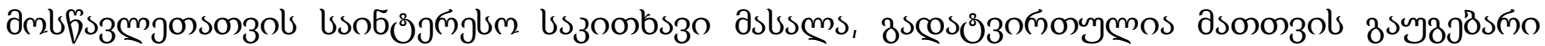

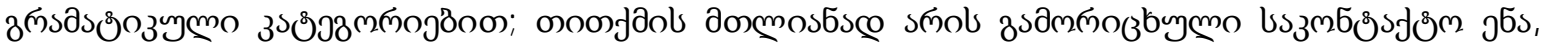

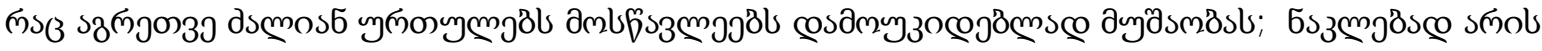

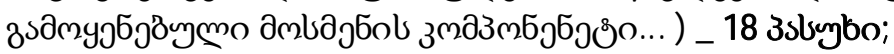

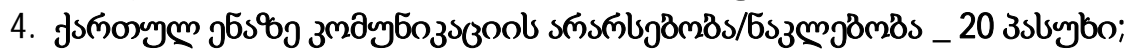

5. usbj

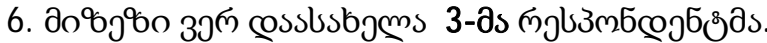

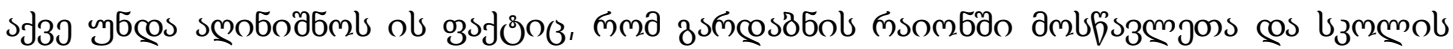

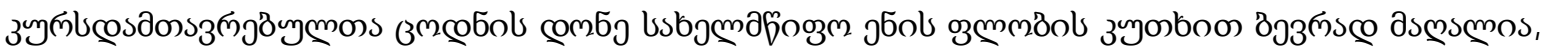

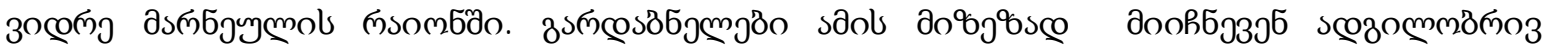

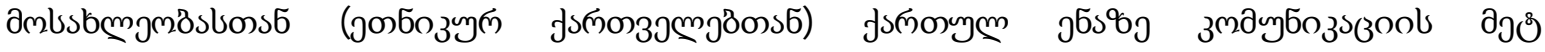

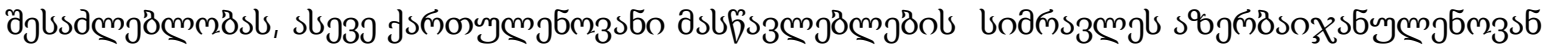

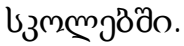

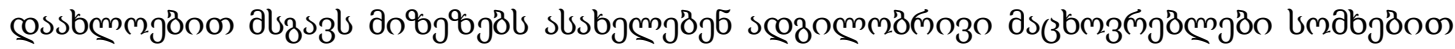

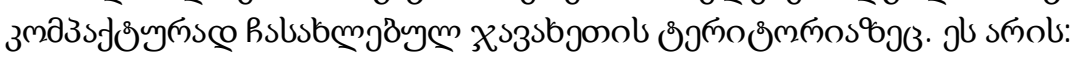

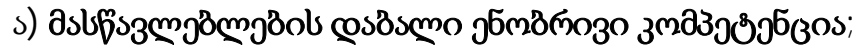

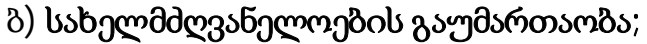

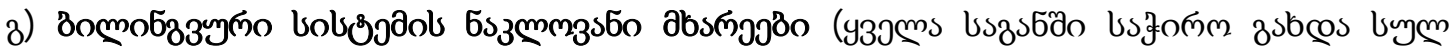

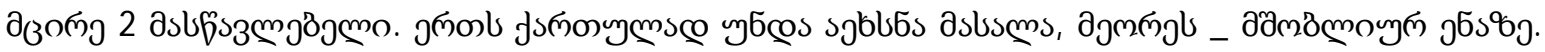

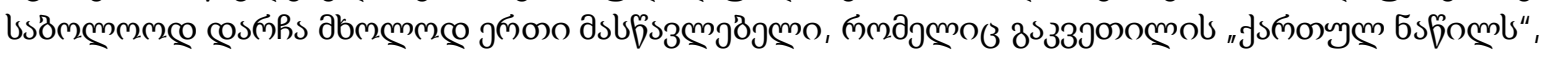

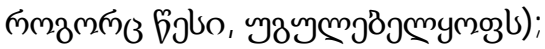

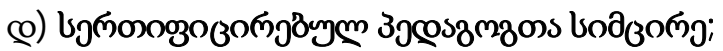

э) удзмल

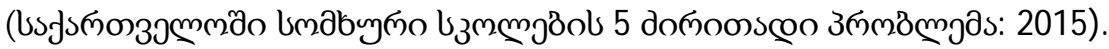

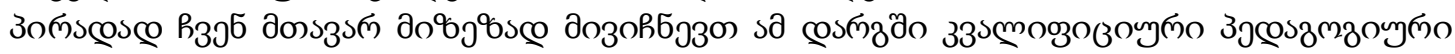

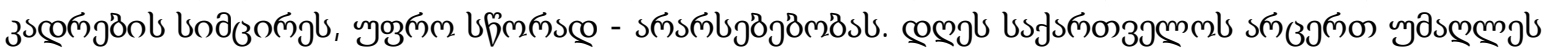




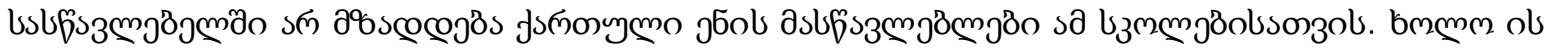

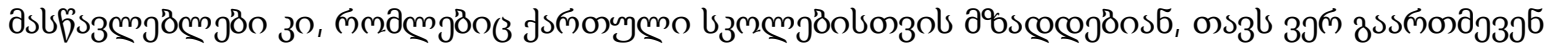

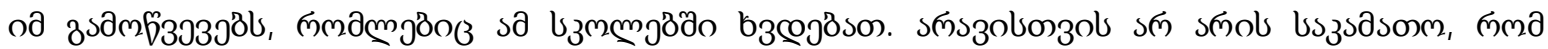

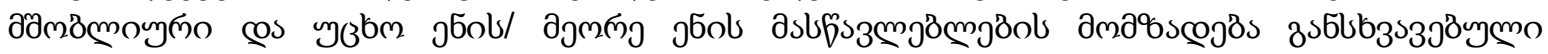

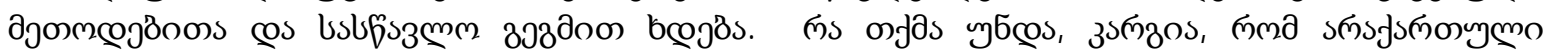

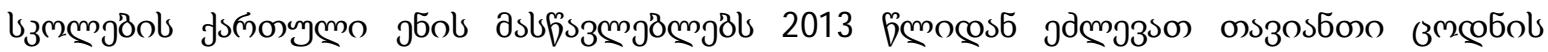

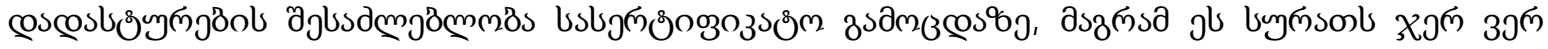
33mol.

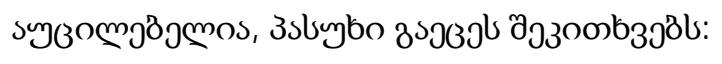

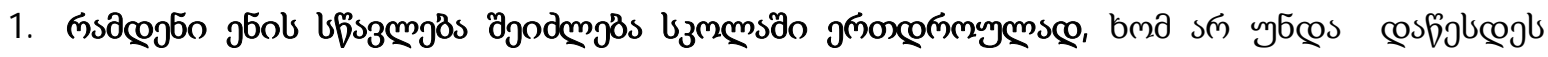

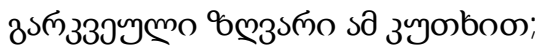

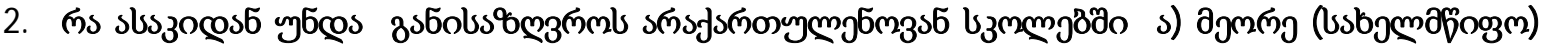

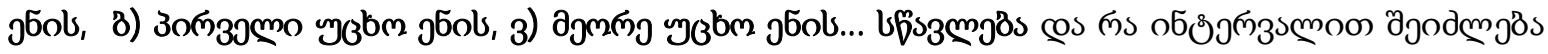

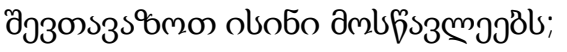

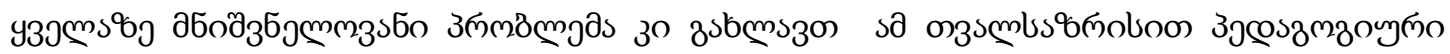

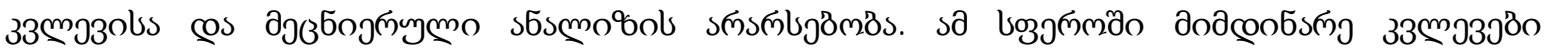

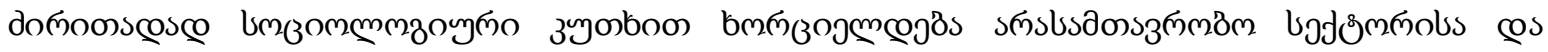

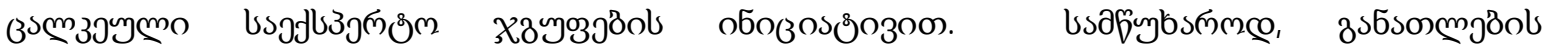

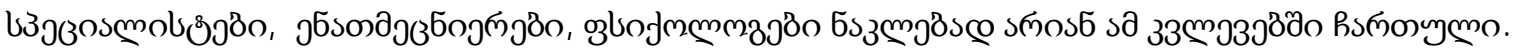

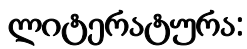

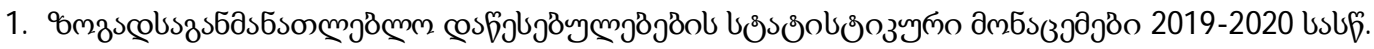

femolsonzol

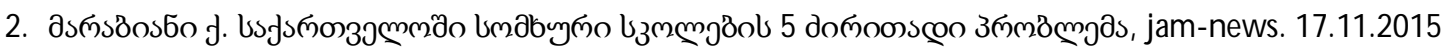

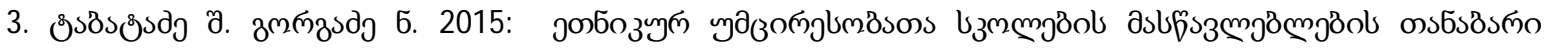

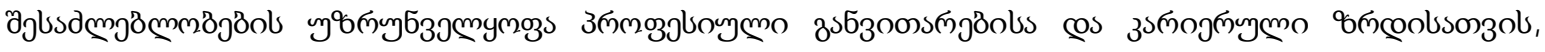

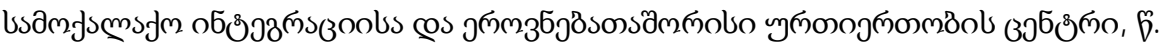

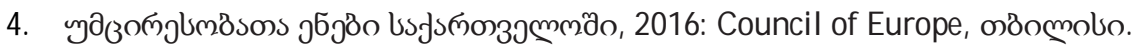

\section{Issues of Teaching Georgian Language in non-Georgian Schools}

\author{
Maglakelidze Natela \\ Ilia State University, Tbilisi
}

\begin{abstract}
Georgia has always been a multilingual country. According to the Law of Georgia on General Education, Georgian is a teaching language in educational institutions. According to the same law, "Georgian citizens, for whom the Georgian is not a native language, have the right of receiving a full general education in their native language, in accordance with the National Curriculum and the rules established by law. Learning the state language is compulsory in these general educational institutions". Teaching process in our schools today is undergoing in accordance with this law.

There are 2313 schools in Georgian at the moment, about $10 \%$ of them are non-Georgian schools: Azerbaijani, Armenian, Russian. Next to the native (Azerbaijani, Armenian, Russian) languages the Georgian language (as an official language) is also taught from the first grade in suche schools where Georgian represents the second language for these students.
\end{abstract}


The main problem for the non-Georgian students is not knowing their official language and hindering them in social integration.

There are some reasons: a) the texts-books of the Georgian language for non-Georgian schools, b) the low competences of Georgian language in teachers are also to be mentioned, c) the most important problem among them is the non-existence of research and theoretical analysis. From this view point only some important events are organized by the NGOs and certain expert groups. Unfortunately specialists of Education, linguists and psychologists are not involved in these researches.

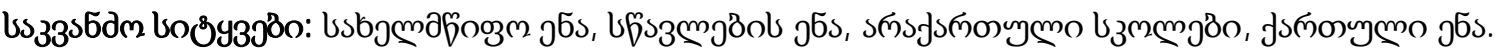
Key words: Teaching language, Official language, non-Georgian schools, Georgian language. 